\title{
Erratum to: Sprout differentiation and mutation induction of garlic (Allium sativum L.) callus exposed to gamma radiation
}

\author{
Hassan H. A. Mostafa ${ }^{1,2} \cdot$ Haiping Wang ${ }^{1} \cdot$ Di Shen $^{1} \cdot$ Yang Qiu $^{1} \cdot$ \\ Xixiang $\mathbf{L i}^{1}$
}

Published online: 7 April 2015

(C) Springer Science+Business Media Dordrecht 2015

\section{Erratum to: Plant Growth Regul (2015) 75:465-471 \\ DOI 10.1007/s10725-014-0009-7}

Unfortunately, in the original publication of the article, the authorship was incorrectly published.
The corrected authorship is given below:

Haiping Wang is the co-first author, Hassan $\mathrm{H}$. A. Mostafa is the first author, and Xixiang Li is the corresponding author of the article.

The online version of the original article can be found under doi:10. 1007/s10725-014-0009-7.

Xixiang $\mathrm{Li}$

lixx0612@163.com

1 Beijing Research Station for Vegetable Crop Gene Resource and Germplasm Enhancement, Ministry of Agriculture, Institute of Vegetables and Flowers, Chinese Academy of Agricultural Sciences, 12 Zhongguancun, Nandajie, Haidian District, Beijing 100081, China

2 Central Laboratory of Organic Agriculture, Agricultural Research Centre, Giza, Egypt 